\title{
積層造形における幾何学的制約を考慮したトポロジー最適化
}

\author{
三木 隆生 ${ }^{* 1}$, 古田 歩 ${ }^{* 2}$, 佐藤 勇気 ${ }^{* 2}$, 山田 崇恭 ${ }^{* 2}$, 泉井 一浩 ${ }^{* 2}$, 西脇 眞二 ${ }^{* 3}$
}

\section{Imposing geometrical constraint in topology optimization for additive manufacturing}

\author{
Takao MIKI ${ }^{* 1}$, Ayumu FURUTA ${ }^{* 2}$, Yuki SATO ${ }^{* 2}$, Takayuki YAMADA*2, \\ Kazuhiro IZUI ${ }^{* 2}$ and Shinji NISHIWAKI*3 \\ ${ }^{*} 1$ Osaka Research Institute of Industrial Science and Technology \\ 2-7-1 Ayumino, Izumi-city, Osaka 594-1157, Japan \\ ${ }^{*} 2,{ }^{* 3}$ Department of Mechanical Engineering and Science, Kyoto University \\ C3, Kyotodaigaku-katsura, Nishikyo-ku, Kyoto 615-8540, Japan
}

Received: 25 December 2018; Revised: 25 March 2019; Accepted: 19 May 2019

\begin{abstract}
Topology optimization has been widely used in industry for designing high performance structures, but these structures are often complicated shape and cannot be manufactured directly. To solve this problem, it is necessary that geometrical constraints for manufacturability be satisfied in the optimization process. This paper proposes a scheme for imposing geometrical constraints, known as overhang constraints, in topology optimization for additive manufacturing (AM). As a feature of AM, when the inclination angle of an overhang is lower than a certain angle, AM components require temporary support materials to prevent the components from collapsing during fabrication. After the fabrication, these support materials are removed mechanically or chemically. As the use of support materials increase, manufacturing costs increase. Consequently, in order to reduce support materials, it is necessary to control the minimal inclination angle of an overhang in topology optimization. In the proposed method, the inclination angle of an overhang is represented using a fictitious physical model described by a steady-state diffusion equation. The overhang constraint can be imposed in the optimization procedure by constraining the value of the fictitious physical field. Several numerical examples are given to show the validity and effectiveness of the proposed method.
\end{abstract}

Keywords : Topology optimization, Additive manufacturing, 3D printing, Overhang, Geometrical constraint

\section{1. 緒言}

トポロジー最適化（Bendsøe and Kikuchi, 1988）は，外形形状のみならず構造物内部に境界が生成されるような 形態の変更も許容する自由度の高い構造最適化の方法である. しかしながら，一般にトポロジー最適化によって 得られる構造は幾何学的に複雑な構造になる場合が多く, 製造が困難である.この問題を解決するためには最適 化の過程において, 製造要件を満たすための制約（以下, 製造制約）を考慮し, 最適構造を求める必要がある.

製造制約の多くは幾何学的な制約であり，現在までに種々の製造法に対する様々な製造制約が提案されている. 例えば機械加工，鋳造など，製造法の多くは固有の加工仕様，加工限界があり，ある寸法以下の形状は加工が極 めて難しくなる．こうした最小寸法に関する制約に対しては加工困難な一定寸法以下の構造の創出を回避する方

\footnotetext{
No.18-00508 [DOI:10.1299/transjsme.18-00508], J-STAGE Advance Publication date : 27 May, 2019

*1 正員，地方独立行政法人大阪産業技術研究所（一594-1157 大阪府和泉市女ゆみ野 2-7-1）

*2 正員, 京都大学大学院工学研究科（干615-8540 京都府京都市西京区京都大学桂 C3）

*3 正員, フェロー, 京都大学大学院工学研究科

E-mail of corresponding author: mikit@tri-osaka.jp
} 
法（Poulsen, 2003; Guest et al., 2004; Zhou et al., 2015）が提案されている. また鋳造やダイカスト，射出成形など 構造物を成形するために型を用いる製造法においては構造物を離型可能な形状にするため，中空形状やアンダー カット形状の創出を回避する方法（Zhou et al., 2002; Xia et al., 2010; Sato et al., 2017）が提案されている.

他方で, 従来の機械加工, 鋳造などに比べ幾何学的に複雑な構造が製造可能な方法として, 積層造形法が近年 注目されている，一般に積層造形法は三次元の CAD データを積層方向に一定の間隔で分割し，二次元の断面デー タをもとに材料を積層していく製造法である.この製造法の性質として, 新たに材料を積層する際に下層で支持 ができない形状をオーバーハングと呼び, 用いる造形装置によって差異はあるが，このオーバーハングの傾斜角 が水平面に対しておよそ 45 度より小さくなると, 造形時に自重で崩れるおそれがあるため, 構造物を支えるため のサポート材が必要となる. サポート材は造形完了後, 不要となるため構造物から機械的, もしくは化学的に取 り除かれる. したがって, サポート材の使用量が増加すると, 製造時間, および材料費が増加し生産性の低下に つながる.また構造物内部にサポート材が発生すると機械加工では除去できない場合もある。サポート材の使用 量を低減するためには，オーバーハングの傾斜角が一定角度以下となる構造を排する設計が必要となる.

こうした一定角度以下のオーバーハングが創出されない幾何学的制約（以下，オーバーハング制約）について も, いくつかの方法が提案されている. Leary ら（2014）は, トポロジー最適化によって得られた最適構造がオー バーハング制約を満たすように形状修正する方法を提案している．この方法は構造を修正する際に構造性能を考 慮しないため, 形状修正後の構造性能が低下する可能性がある. Langelaar（2016）や Gaynor ら（2016）は最適化 の過程でオーバーハング制約を考慮する方法を提案している．しかしながら，これらの方法は最適化の過程にお いて制約に違反する構造を許容せず設計空間に制限を与えるため, 初期構造に対する依存性が高く, オーバーハ ング制約は満たすものの高性能な構造を得るのが難しい問題を持つ.

そこで, 本研究では設計空間に制限を与えることなく最適化の過程では制約の違反を許容し, 最適構造におい ては制約が満たされる幾何学的制約の実現を目指す。

\section{2. トポロジー最適化}

\section{$2 \cdot 1$ レベルセット法に基づく構造最適化問題の定式化}

トポロジー最適化の基本的な考え方は, 最適構造を包含する固定設計領域 $D$ と, 次式に示す特性関数 $\chi_{\Omega}$ を導 入することにより, 構造最適化問題を材料分布問題に置き換えることである.

$$
\chi_{\Omega}(x)=\left\{\begin{array}{l}
1 \text { for } x \in \Omega \\
0 \text { for } x \in D \backslash \Omega
\end{array}\right.
$$

ここで, $\Omega$ は物体領域を表し, $\boldsymbol{x}$ は物体領域 $\Omega$ のある点を示す.この特性関数により任意のトポロジーをもつ構造 を表現することが可能となる. しかしながら, この特性関数は無限小の間隔で不連続な值を許容するため, トポロ ジー最適化問題は不良設定問題であることが知られている. したがって, 設計空間を緩和, 凸化, あるいは正則化 によって良設定問題に置き換える必要があり，その代表的な方法として均質化設計法 (Bendsøe and Kikuchi, 1988) がある．また，正規化された密度を用いて材料パラメータを連続関数として設計空間の凸化を行うSIMP（Solid Isotropic Material with Penalization) 法 (Bendsøe and Sigmund, 1999) があり, 現在最も広く用いられている. 他方 で, レベルセット法に基づく形状最適化法 (Wang et al., 2003; Allaire et al., 2004) やトポロジー最適化法 (山田他, 2009; Yamada et al., 2010) も提案されている. これらの方法では, レベルセット関数と呼ばれるスカラー関数を導 入し，その零等位面により物体の境界を表現する. 前者の方法は, レベルセット関数を符号付距離関数として定義 し, ハミルトンーヤコビ方程式により更新する形状最適化の方法であり, 後者の方法は, レベルセット関数を区分 一定值関数として定義し, 時間発展方程式により更新するトポロジー最適化の方法である. 本研究では, Yamada ら (2010) によって提案された後者の方法を用いる. この方法では, レベルセット関数は次のように定義される.

$$
\begin{cases}0<\phi(x) \leq 1 & \text { for } \boldsymbol{x} \in \Omega \backslash \partial \Omega \\ \phi(x)=0 & \text { for } \boldsymbol{x} \in \partial \Omega \\ -1 \leq \phi(x)<0 & \text { for } \boldsymbol{x} \in D \backslash \Omega\end{cases}
$$


また，レベルセット関数により特性関数を表現すると次のようになる.

$$
\chi_{\phi}(\phi)=\left\{\begin{array}{l}
1 \text { for } \phi \geq 0 \\
0 \text { for } \phi<0
\end{array}\right.
$$

上述のレベルセット関数を用いて，構造最適化問題は目的汎関数を $F ，$ 体積制約に関する制約汎関数を $G$ とする と，次のように記述される。

$$
\begin{aligned}
& \inf _{\phi} F\left(\chi_{\phi}(\phi), \phi\right)=\int_{D} f_{d}(\boldsymbol{x}) \chi_{\phi}(\phi) d \Omega+\int_{\Gamma} f_{b}(\boldsymbol{x}) d \Gamma \\
& \text { subject to } G\left(\chi_{\phi}(\phi)\right)=\int_{D} \chi_{\phi}(\phi) d \Omega-V_{\max }
\end{aligned}
$$

ここで, $f_{d}(\boldsymbol{x}), f_{b}(\boldsymbol{x})$ は固定設計領域，および領域境界における目的汎関数の被積分関数である．また， $V_{\max }$ は体 積制約の上限值を表す.さらに，この構造最適化問題をラグランジュ未定乗数法を用いて無制約問題に置き換え る. ラグランジアンを $\bar{F}$, 式 (5) に関するラグランジュ乗数を $\lambda$ とすれば, 次式となる.

$$
\inf _{\phi} \bar{F}\left(\chi_{\phi}(\phi), \phi\right)=F\left(\chi_{\phi}(\phi), \phi\right)+\lambda\left(\int_{D} \chi_{\phi}(\phi) d \Omega-V_{\max }\right)
$$

本研究では, 上式を解くことにより，最適構造を得る.

\section{$2 \cdot 2$ 時間発展方程式に基づくレベルセット関数の更新}

本研究では, Yamada ら（2010）の方法に基づき, 最適なレベルセット関数分布を求める問題を, 時間発展方程 式を解く問題へと置き換える. 仮想的な時間 $t$ を導入し, レベルセット関数を時間 $t$ の関数とすると,レベルセッ 卜関数は次式で表される反応拡散方程式によって更新される.

$$
\frac{\partial \phi}{\partial t}=-K\left(\delta \bar{F}-\tau \nabla^{2} \phi\right)
$$

ここで， $K$ は比例定数であり， $\delta \bar{F}$ は設計感度である.レベルセット関数は固定設計領域内の至るところで不連続 性を持ちうるため, 右辺第二項にレベルセット関数の勾配によって表現される項を付加することによって設計空 間の正則化が行われている. また, 正則化係数 $\tau$ の調整により, 最適構造の幾何学的複雑さの定性的な調整が可 能である. (Yamada et al., 2010)この反応拡散方程式によりレベルセット関数を逐次更新することで，最適構造を 表現するレベルセット関数分布が得られる.

\section{3. 積層造形法における幾何学的制約法}

\section{$3 \cdot 1$ 積層造形法における幾何学的要件}

最初に，積層造形法における幾何学的要件を明確化する. 図 1 （a）にオーバーハングの例を示す. サポート材 を使用せずに造形を行うためには，オーバーハングが水平面に対して一定角度を下回る形状を避けなければなら ない.したがって，積層造形法における製造制約はこのようなオーバーハングを排する幾何学的制約を考慮しな ければならない。

\section{$3 \cdot 2$ 平滑化特性関数に基づく幾何学的制約法}

次に, 前述の幾何学的要件を満たすための目的汎関数を定式化する.眓 1（b）に示すように，物体領域で $\psi=1$, 空洞領域で $\psi=0$ となり, 物体境界で 1 から 0 に滑らかに変化する $\psi$ を考える. このとき, $\boldsymbol{q}$ は積層方向を表し, $\nabla \psi /|\nabla \psi|$ は物体境界における空洞領域から物体領域に向かう法線ベクトルを表している. このような $\psi$ をを固定設 計領域内に分布できれば, 物体境界上のある点における傾斜角 $\theta$ の余弦 $\cos \theta$ を $\boldsymbol{q} \cdot \nabla \psi /|\nabla \psi|$ で表すことができる. そして, サポート材を要せずに造形ができる角度を $\theta_{0}$ とすれば，その余弦 $\cos \theta_{0}$ の值と比較することによってサ ポート材を要するオーバーハングか否かの判別ができる.なお，物体境界における法線は符号付距離関数を用い て求める方法などが考えられるが, 繰り返し計算を要するため計算コストが大きくなる恐れがある. したがって, 本研究では平滑な特性関数を導入することにより, 容易に幾何学的制約を課す方法を提案する. すなわち, 次式 で表されるような拡散項と外力項のみからなる偏微分方程式を考える。 


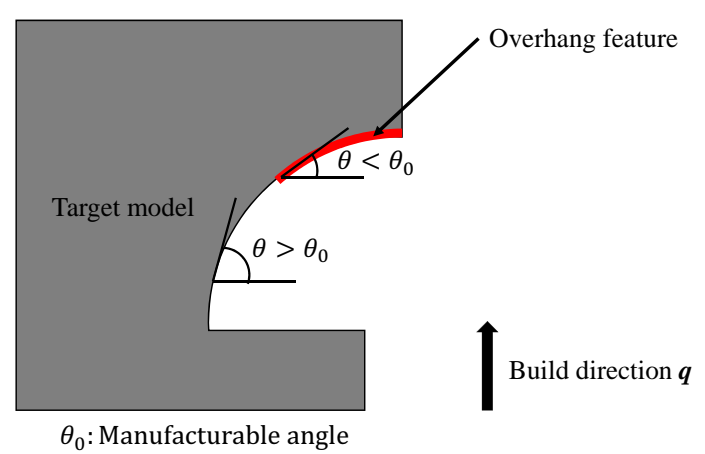

(a)

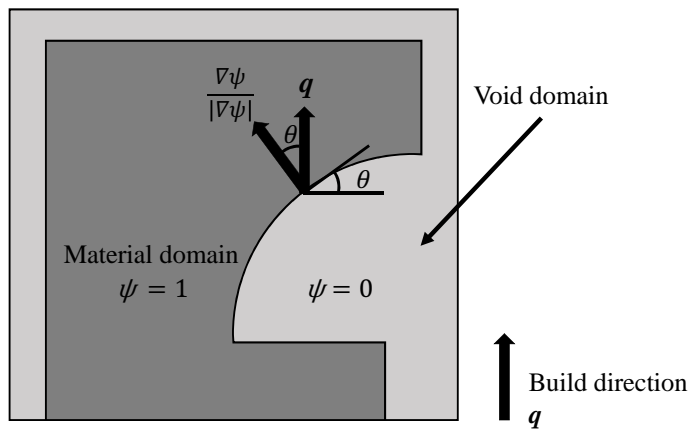

(b)

Fig. 1 (a) Obstacle in additive manufacturing and (b) Desired $\psi$ characteristics.

$$
\begin{cases}-c L^{2} \nabla^{2} \psi=\chi_{\phi}(1-\psi)-\left(1-\chi_{\phi}\right) \psi & \text { in } D \\ \boldsymbol{n} \cdot \nabla \psi=0 & \text { on } \Gamma\end{cases}
$$

ここで， $D$ は解析領域， $\Gamma$ は領域境界を表し， $c$ は拡散係数， $L$ は解析領域の積層方向に関する代表長さを表す。ま た $\boldsymbol{n}$ は解析領域の外向き単位法線べクトルを表す。拡散係数 $c$ を十分小さく設定することで， $\psi$ は物体領域で 1 , 空洞領域で 0 となり，物体境界の法線方向に沿った勾配が生じる。そして，物体境界上のある点における傾斜角 $\theta$ の余弦 $\cos \theta$ とサポート材を要せずに造形可能な傾斜角 $\theta_{0}$ の余弦 $\cos \theta_{0}$ の差が 0 より大きければ，オーバーハン グ制約に違反していることがわかる.したがって，そのような領域を排するには次の汎関数を最小化すればよい.

$$
F_{O}=\int_{D} \max \left(L \boldsymbol{q} \cdot \nabla \psi /|\nabla \psi|-L \cos \theta_{0}, 0\right) d \Omega
$$

しかしながら， $|\nabla \psi|$ が 0 となる場合，上式は無限大に発散する。また， max 関数内の一つ目の項が 0 近傍におい て勾配が不連続となるため, 次の汎関数でオーバーハング制約の評価を行う.

$$
F_{O}=\int_{D} \max \left(L \boldsymbol{q} \cdot \nabla \psi-L|\nabla \psi| \cos \theta_{0}, 0\right)^{2} d \Omega
$$

上式を物理的な性能を表す目的汎関数と同時に最小化することにより，物理的な性能と積層造形法における製造 性を同時に考慮したトポロジー最適化が可能となる.

\section{$3 \cdot 3$ サポート材の評価方法}

オーバーハング制約に違反している領域は構造を支持するためのサポート材が必要となる．ここではサポート 材を要する領域の表現方法について考える. 図 2 に示すように, サポート材を要する領域で $\xi=1$, それ以外の領 域で $\xi=0$ となるような分布をもつ $\xi$ は, 前述の幾何学的制約法の考えに基づき, 拡散項, 移流項, 外力項から なる次式の偏微分方程式によって表すことができる.

$$
\begin{cases}L^{2} \operatorname{div}(\boldsymbol{A} \cdot \nabla \boldsymbol{\xi})+L V \boldsymbol{q} \cdot \nabla \xi & \\ \quad=\alpha\left\{\max \left(L \boldsymbol{q} \cdot \nabla \psi-L|\nabla \psi| \cos \theta_{0}, 0\right)\left(1-\chi_{\phi}\right)(1-\xi)-\chi_{\phi} \xi\right\} & \text { in } D \\ \boldsymbol{\xi}=0 & \text { on } \Gamma \\ \boldsymbol{n} \cdot \nabla \boldsymbol{\xi}=0 & \text { on } \partial D \backslash \Gamma\end{cases}
$$

ここで， $D$ は解析領域， $\Gamma$ は領域境界を表し， $A$ は拡散係数テンソル， $V$ は流速， $\alpha$ は外力項の係数， $L$ は解析領 域の積層方向に関する代表長さを表す。また $\boldsymbol{n}$ は解析領域の外向き単位法線べクトルを表す．拡散係数テンソル $A$ は，積層方向成分を積層方向と直交する成分よりも大きく設定する．すなわち，A は以下のように表される.

$$
\boldsymbol{A}=\boldsymbol{q} \otimes \boldsymbol{q}+\varepsilon \sum_{i=1}^{N-1} \boldsymbol{e}_{i}^{\perp} \otimes \boldsymbol{e}_{i}^{\perp}
$$




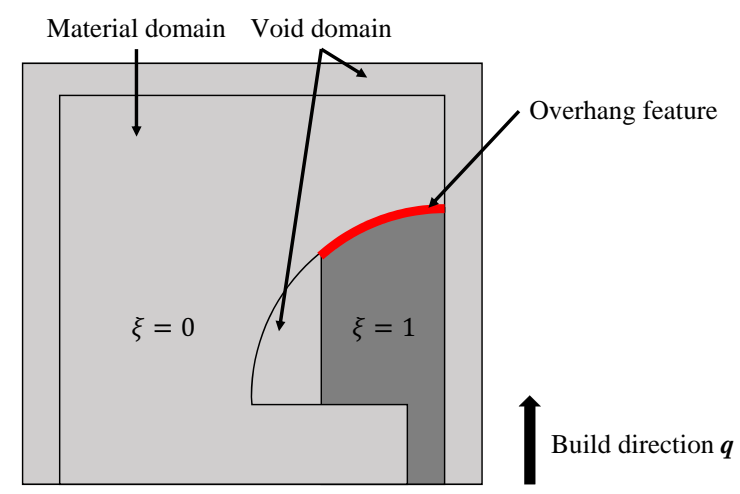

Fig. 2 Desired $\xi$ characteristics.

$N$ は空間の次元, $\boldsymbol{e}_{i}^{\perp}$ は $\boldsymbol{q}$ の直交補空間における正規直交規定を表し, $\varepsilon$ は微小な定数である. 外力項の係数 $\alpha$ を 十分大きく設定することで, $\xi$ はサポート材を要する領域で 1 , その他の領域で 0 となり, 所望の分布が得られる.

\section{4. 最適化問題の定式化}

本研究では, 平均コンプライアンス最小化問題を扱う. 境界 $\Gamma_{u}$ で固定された等方線形弾性体 $\Omega$ の境界 $\Gamma_{t}$ に表 面力 $\boldsymbol{t}$ が作用しているとする. 変位場 $\boldsymbol{u}$, 弾性テンソルを $\boldsymbol{C}$, ひずみテンソルを $\boldsymbol{\varepsilon}(\boldsymbol{u})=\left(\nabla \boldsymbol{u}+\nabla \boldsymbol{u}^{\mathrm{T}}\right) / 2$ とすると, 平均コンプライアンス最小化問題の目的汎関数は次のように記述される.

$$
F_{C}=\int_{\Gamma_{t}} \boldsymbol{t} \cdot \boldsymbol{u} d \Gamma
$$

したがって，オーバーハング制約を考慮した平均コンプライアンス最小化問題は次のように定式化される.

$$
\begin{aligned}
\inf _{\phi} \quad F & =(1-w) F_{C}+w F_{O} \\
\text { subject to : } G_{1} & =\int_{D} \chi_{\phi} d \Omega-V_{\max } \leq 0 \\
E_{1} & =\int_{\Gamma_{t}} \boldsymbol{t} \cdot \boldsymbol{v} d \Gamma-\int_{D} \boldsymbol{\varepsilon}(\boldsymbol{v}): C: \boldsymbol{\varepsilon}(\boldsymbol{u}) d \Omega=0 \\
E_{2} & =-\int_{D} c L^{2} \nabla \tilde{\psi} \cdot \nabla \psi d \Omega-\int_{D} \tilde{\psi} \psi d \Omega-\int_{D} \tilde{\psi} \chi_{\phi} d \Omega=0
\end{aligned}
$$

ここで, $\boldsymbol{v}, \tilde{\psi}$ は試験関数である. 式 (14)において, 右辺第一項は平均コンプライアンス, 第二項はオーバーハング 制約の目的汎関数である. また， $w$ は重み係数である. 上記の最適化問題において， $G_{1}$ は体積制約であり， $V_{\max }$ は体積の上限值を表す， $E_{1}$ は等方線形弾性体の平衡方程式の弱形式であり， $E_{2}$ は式 $(8)$ の弱形式である.

\section{5. 数 值 実 装 法}

\section{$5 \cdot 1$ 最適化アルゴリズム}

本研究における最適化アルゴリズムを次に示す.

Step 1 初期構造を表現するレベルセット関数を与える.

Step 2 有限要素法を用いて支配方程式（16），(17）の求解を行う.

Step 3 目的汎関数を計算し, 収束していれば最適化を終了する，収束していなければ，続いて有限要素法を用 いた随伴方程式の求解を行う.

Step 4 設計感度を計算する.

Step 5 反応拡散方程式（7）に基づきレベルセット関数を更新し, Step 2 へと戻る. なお, 平均コンプライアン ス最小化問題は自己随伴問題であるため, Step 3 では，オーバーハング制約に関する随伴方程式の求解のみを 行う. 


\section{$5 \cdot 2$ 感度解析}

上述のオーバーハング制約付き平均コンプライアンス最小化問題の設計感度を導出する.ここでは本研究で提 案したオーバーハング制約に関する感度の導出のみを記述する．まず，ラグランジアンを次のように定義する.

$$
\overline{F_{O}}=F_{O}+E_{2}
$$

このラグランジアンの変分は以下で表される.

$$
\delta \bar{F}_{O}=\delta F_{O}+\delta E_{2}=\delta_{\psi} F_{O}+\delta_{\psi} E_{2}+\delta_{\chi_{\phi}} E_{2}
$$

ここで, 状態変数 $\psi$ の変分が含まれる項が 0 となるように随伴方程式を定義する.

$$
\begin{aligned}
& \delta_{\psi} F_{O}=\lim _{\varepsilon \rightarrow 0} \frac{F_{O}(\psi+\varepsilon \delta \psi)-F_{O}(\psi)}{\varepsilon} \\
& =\int_{D} 2 \Theta(\psi)\left(\boldsymbol{q}-\frac{\nabla \psi}{|\nabla \psi|} \cos \theta_{0}\right) \cdot \nabla \delta \psi d \Omega \\
& =\int_{\Gamma} \boldsymbol{n} \cdot\left[\left(2 \Theta(\psi)\left(\boldsymbol{q}-\frac{\nabla \psi}{|\nabla \psi|} \cos \theta_{0}\right)\right] \delta \psi d \Gamma-\int_{D} \nabla \cdot\left[\left(2 \Theta(\psi)\left(\boldsymbol{q}-\frac{\nabla \psi}{|\nabla \psi|} \cos \theta_{0}\right)\right] \delta \psi d \Omega\right.\right. \\
& \Theta(\psi)=\max \left(\boldsymbol{q} \cdot \nabla \psi-|\nabla \psi| \cos \theta_{0}, 0\right) \\
& \delta_{\psi} E_{2}=\lim _{\varepsilon \rightarrow 0} \frac{E_{2}(\psi+\varepsilon \delta \psi, \tilde{\psi})-E_{2}(\psi, \tilde{\psi})}{\varepsilon} \\
& =-\int_{D} c L^{2} \nabla \tilde{\psi} \cdot \nabla \delta \psi d \Omega-\int_{D} \tilde{\psi} \delta \psi d \Omega \\
& =-\int_{\Gamma} \boldsymbol{n} \cdot\left(c L^{2} \nabla \tilde{\psi}\right) \delta \psi d \Gamma+\int_{D}\left(c L^{2} \nabla^{2} \tilde{\psi}-\tilde{\psi}\right) \delta \psi d \Omega \\
& \left\{\begin{array}{l}
c L^{2} \nabla^{2} \tilde{\boldsymbol{\psi}}-\tilde{\psi}-\nabla \cdot\left[2 \Theta(\psi)\left(\boldsymbol{q}-\frac{\nabla \psi}{|\nabla \psi|} \cos \theta_{0}\right)\right]=0 \text { in } D \\
-\boldsymbol{n} \cdot c L^{2} \nabla \tilde{\psi}+\boldsymbol{n} \cdot\left[\left(2 \Theta(\psi)\left(\boldsymbol{q}-\frac{\nabla \psi}{|\nabla \psi|} \cos \theta_{0}\right)\right]=0 \text { on } \Gamma\right.
\end{array}\right.
\end{aligned}
$$

したがって，オーバーハング制約の設計感度は以下となる.

$$
\delta \overline{F_{O}}=\delta_{\chi_{\phi}} E_{2}=-\tilde{\psi}
$$

また，式（14）-（17）で定義された最適化問題の設計感度は，各々の設計感度を正規化した次式を用いる.

$$
\delta \bar{F}=(1-w) \frac{\delta \bar{F}_{C} \int_{D} d \Omega}{\int_{D}\left|\delta \bar{F}_{C}\right| d \Omega}+w \frac{\delta \bar{F}_{O} \int_{D} d \Omega}{\int_{D}\left|\delta \bar{F}_{O}\right| d \Omega}+\lambda
$$

ここで, $w$ は重み係数であり, $\lambda$ は体積制約に対するラグランジュ乗数である.

\section{6. 数 值 計 算 例}

本章では, 提案する手法を二次元の平均コンプライアンス最小化問題へと適用し, 本提案手法の妥当性を検証 する.

\section{1 平均コンプライアンス最小化問題}

二つの数值例により, 本提案手法の妥当性を検証した. 図 3 に設計問題 1 の固定設計領域及び境界条件を示す. 固定設計領域は $0.8 \mathrm{~m} \times 0.4 \mathrm{~m}$ の長方形領域とした。境界条件は, 設計領域下端の左側を完全変位拘束, 右側を $y$ 方向変位拘束し，下端中央に下向きに表面力を作用させる. 図 4 に設計問題 2 の固定設計領域及び境界条件を示 す. 固定設計領域は $1.0 \mathrm{~m} \times 0.4 \mathrm{~m}$ の長方形領域とした。境界条件は, 設計領域左端を完全変位拘束し, 右端中央 に下向きに表面力を作用させる．いずれの場合も解析モデルの材料は等方線形弾性体を仮定し，ヤング率は 210 $\mathrm{GPa}$ ，ポアソン比は 0.31 とした。体積の上限值は設計領域の体積の $60 \%$ とした. 式（8）に含まれる拡散係数 $c$ は $1 \times 10^{-4}$ とした. 


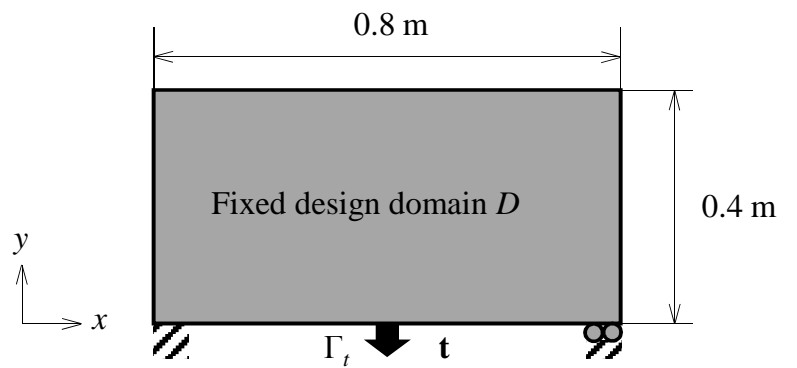

Fig. 3 Fixed design domain and boundary conditions for the design problem 1.

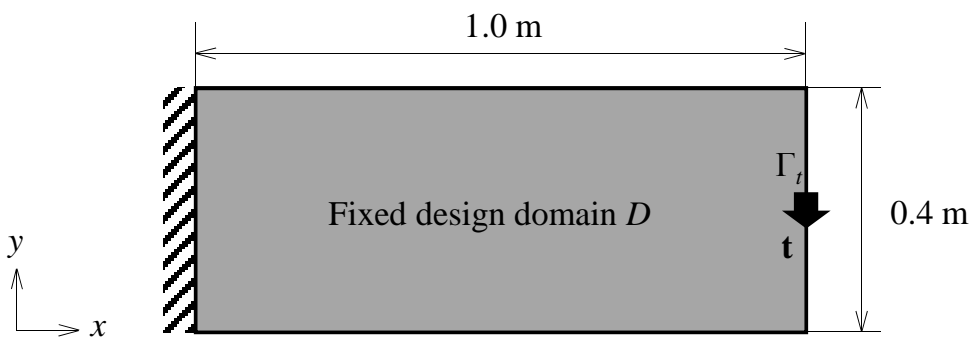

Fig. 4 Fixed design domain and boundary conditions for the design problem 2.

\section{6·1·1 正則化係数, 重み係数が最適構造に与える影響}

はじめに, 正則化係数 $\tau$, および重み係数 $w$ の設定が最適構造に与える影響を検討した。初期構造は, 設計領 域全体を物体領域が占めるものとした．積層方向を $y$ 軸の正方向とし，造形可能な角度を $\theta_{0}=\pi / 4$ とした. 問題 設定 $1 ， 2$ に対して，正則化係数 $\tau$ をそれぞれ $5 \times 10^{-4}, 1 \times 10^{-3}$, 重み係数 $w$ をそれぞれ $0,0.05,0.10,0.15$ と 設定して最適化を行った．得られた最適構造を図 5, 図 6 に黒色で示し，サポート材を前述の評価方法に基づき灰 色で示す. 拡散係数 $\tau$ によって構造の幾何学的複雑さが変化し, 重み係数 $w$ を大きくしていくことでサポート材 を低減できることがわかる，なお，各係数を設定するための具体的な手続きとしては，まず製造可能な形状とな るよう拡散係数の調整を行い, その後幾何学的制約が満足されるよう, 重み係数を調整する方法などが考えられ る. また，問題設定 2 においては重み係数を大きくしていくと，図 6(d), (h) に見られる, 先鋭な形状が局所的に 創出される. 本研究で定式化した幾何学的制約においては, 設定した角度と物体境界上のある点における角度と の比較しか行っていないため, このような特異点を持つ形状の創出を許容する. しかしながら，無制約の場合と 比較するとサポート材を低減できることは明らかであり，製造時においては図に示すように微量のサポートを付 与することによって製造可能である.

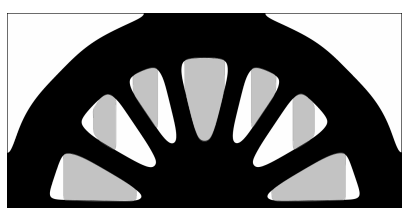

(a) $\tau=5 \times 10^{-4}, w=0$

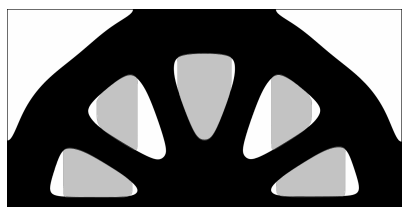

(e) $\tau=1 \times 10^{-3}, w=0$

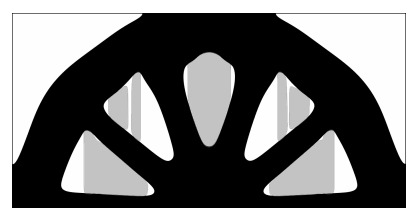

(b) $\tau=5 \times 10^{-4}, w=0.05$

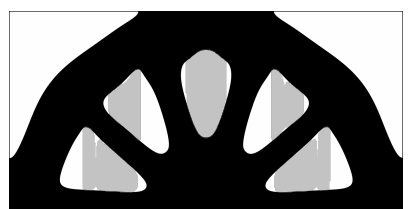

(f) $\tau=1 \times 10^{-3}, w=0.05$

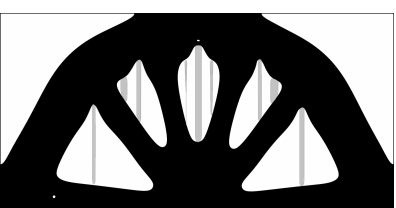

(c) $\tau=5 \times 10^{-4}, w=0.10$

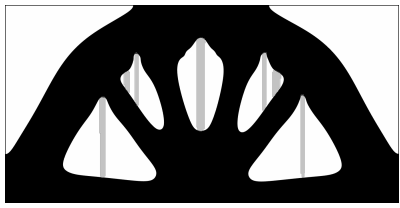

(g) $\tau=1 \times 10^{-3}, w=0.10$

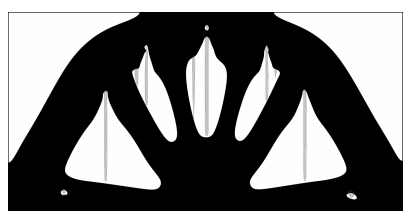

(d) $\tau=5 \times 10^{-4}, w=0.15$

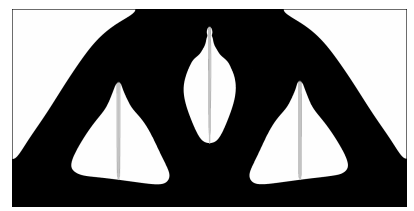

(h) $\tau=1 \times 10^{-3}, w=0.15$

Fig. 5 Optimal configurations obtained for various values of $\tau$ and $w$ of design problem 1. 


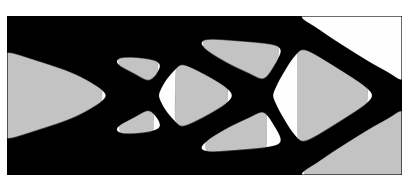

(a) $\tau=5 \times 10^{-4}, w=0$

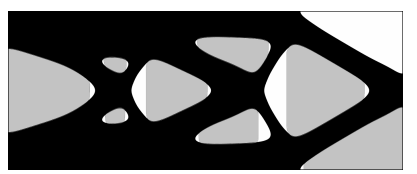

(e) $\tau=1 \times 10^{-3}, w=0$

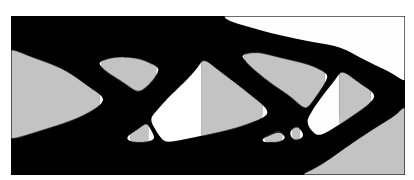

(b) $\tau=5 \times 10^{-4}, w=0.05$

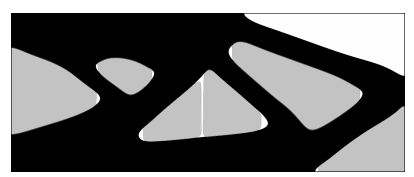

(f) $\tau=1 \times 10^{-3}, w=0.05$

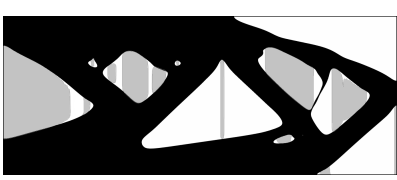

(c) $\tau=5 \times 10^{-4}, w=0.10$

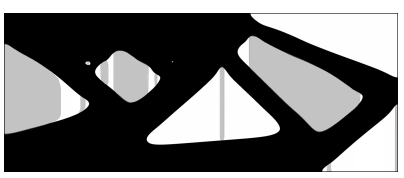

(g) $\tau=1 \times 10^{-3}, w=0.10$

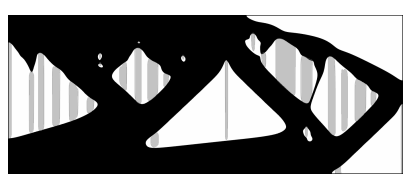

(d) $\tau=5 \times 10^{-4}, w=0.15$

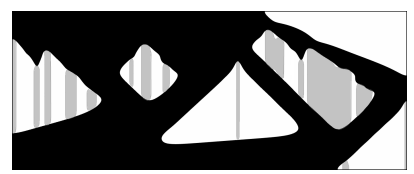

(h) $\tau=1 \times 10^{-3}, w=0.15$

Fig. 6 Optimal configurations obtained for various values of $\tau$ and $w$ of design problem 2.

\subsection{2 初期構造が最適構造に与える影響}

問題設定 1 , 問題設定 2 に対して, 異なる初期構造を設定し, 最適化を行った。問題設定 1 では, 初期構造を, 設計領域全体を物体領域が占める構造 (Case1), 多数の穴の開いた構造 (Case2), 設計領域の下半分が物体領域で占 められている構造 (Case3) とした. 問題設定 2 では初期構造を, 設計領域全体を物体領域が占める構造 (Case1), 多 数の穴の開いた構造 (Case2), 設計領域の上半分が物体領域で占められている構造 (Case3) とした. いずれの場合も 積層方向は $y$ 軸正方向として設定し, 造形可能な角度を $\theta_{0}=\pi / 4$ とした. 重み係数 $w$ は問題設定 1 では $w=0.08$, 問題設定 2 では $w=0.1$ とした. 図 7 , 図 8 に問題設定 1 , 問題設定 2 の初期構造, 最適化過程, 最適構造を示す. 本研究で提案する手法は初期構造に対するオーバーハング制約の違反を許容する. Case 2 の初期構造はオーバーハ ング制約に違反しているが, それぞれの最適構造を比べるとほぼ同様の構造が得られていることから, 初期構造 に対する制約はないことがわかる.

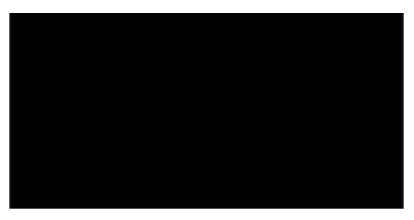

Initial shape

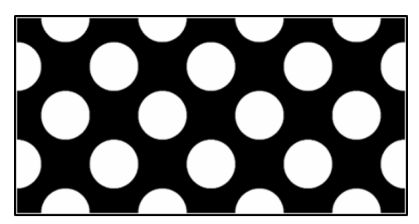

Initial shape

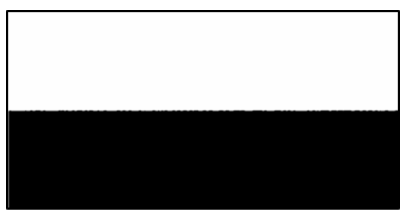

Initial shape

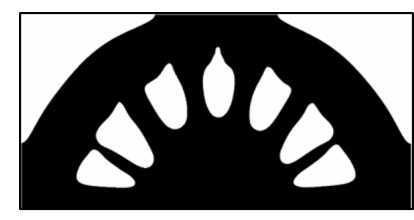

Intermediate result

(a) Case 1

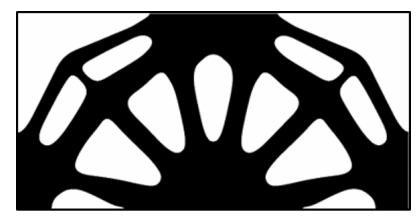

Intermediate result

(b) Case 2

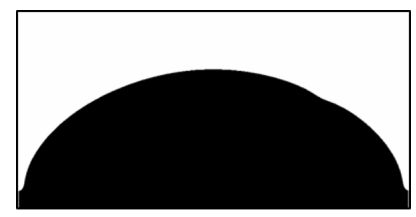

Intermediate result

(c) Case 3

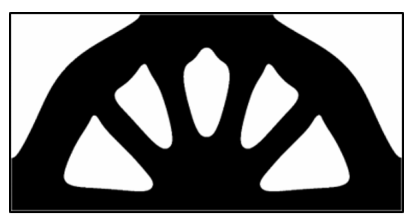

Optimal configuration

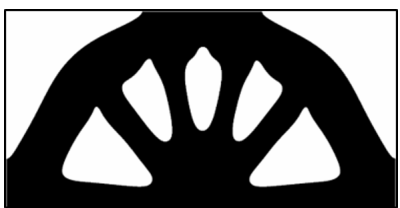

Optimal configuration

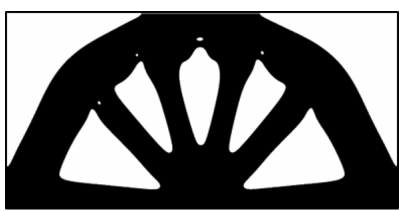

Optimal configuration

Fig. 7 Initial configurations, intermediate results and optimal configurations of design problem 1. 


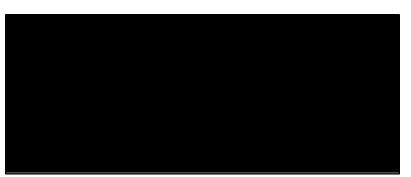

Initial shape

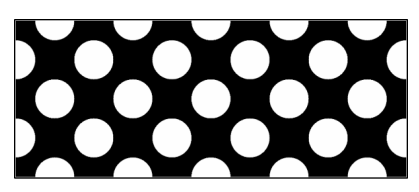

Initial shape

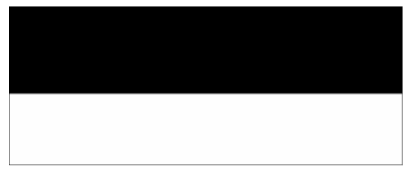

Initial shape

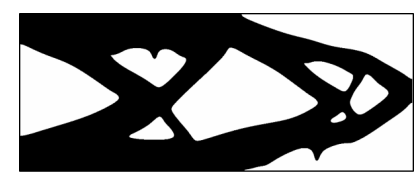

Intermediate result

(a) Case 1

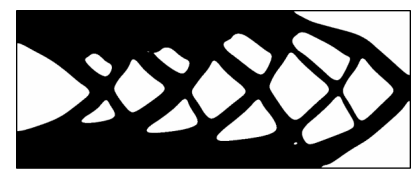

Intermediate result

(b) Case 2

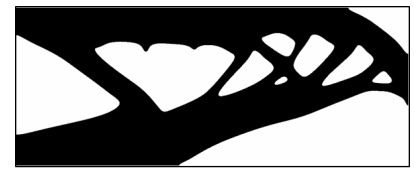

Intermediate result

(c) Case 3

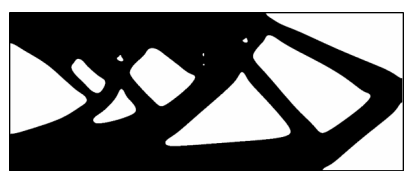

Optimal configuration

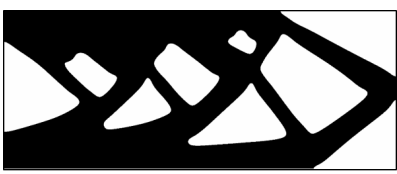

Optimal configuration

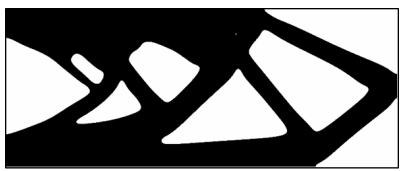

Optimal configuration

Fig. 8 Initial configurations, intermediate results and optimal configurations of design problem 2.

\subsection{3 積層方向が最適構造に与える影響}

積層方向の設定が最適構造に与える影響を検討した。問題設定 1 に対して，積層方向を，y軸負方向， $x$ 軸正方 向と設定し最適化を行った。初期構造は設計領域全体を物体領域が占めるものとし, 造形可能な角度は $\theta_{0}=\pi / 4$, 重み係数は $w=0.08$ とした。得られた最適化構造を図 9 に示す。設定したそれぞれの積層方向に応じて適切な最 適構造が得られていることがわかる。

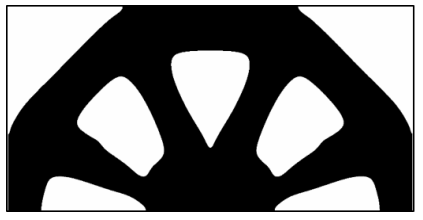

(a) Build direction along negative direction of $y$-axis

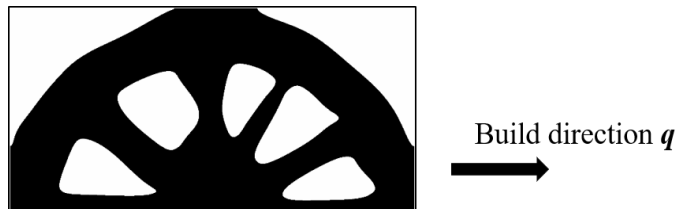

(b) Build direction along positive direction of $x$-axis

Fig. 9 Optimal configurations obtained for various settings of build direction.

7. 結 言

本研究では，積層造形法に関する幾何学的制約を考慮した新しいトポロジー最適化手法を構築した。本研究の 成果を以下に示す。

1. 積層造形における幾何学的要件を明確にし，平滑化関数に基づく目的汎関数の定式化によって幾何学的制約 を課す方法を提案した。

2. 最適設計問題の定式化に基づき，随伴変数法による感度解析を行い，有限要素法による状態場及び随伴場解 析，レベルセット関数の更新を行うことで幾何学的制約を考慮した最適化アルゴリズムを構築した。

3. 設計問題を通して，本研究で提案する方法の有効性と妥当性の検証を行った。まず，重み係数を適切に設定 することにより，サポート材を低減できることを示した。次に，制約違反を含む初期構造においても，最適 化が実行されることを示した。最後に，規定した積層方向に応じて適切な構造が得られることを示した。 
Allaire, G., Jouve, F. and Michailidis, G., Thickness control in structural optimization via a level set method, Structural and Multidisciplinary Optimization, Vol.53, No.6 (2016), pp.1349-1382.

Allaire, G., Jouve, F. and Toader, A.M., Structural optimization using sensitivity analysis and a level-set method, Journal of Computational Physics, Vol.194, No.1 (2004), pp.363-393.

Bendsoe, M.P. and Kikuchi, N., Generating optimal topologies in structural design using a homogenization method, Computer Methods in Applied Mechanics and Engineering, Vol.71, No.2 (1988), pp.197-224.

Bendsoe, M.P. and Sigmund, O., Material interpolation schemes in topology optimization, Archive of Applied Mechanics, Vol.69 (1999), pp.635-654.

Chen, S., Wang, M.Y. and Liu, A.Q., Shape feature control in structural topology optimization, Computer-Aided Design, Vol.40, No.9 (2008), pp.951-962.

Guest, J.K., Imposing maximum length scale in topology optimization, Structural and Multidisciplinary Optimization, Vol.37, No.5 (2009), pp.463-473.

Guest, J.K., Prévost, J.H. and Belytschko, T., Achieving minimum length scale in topology optimization using nodal design variables and projection functions, International Journal for Numerical Methods in Engineering, Vol.61, No.2 (2004), pp.238-254.

Guo, X., Zhang, W. and Zhong, W., Explicit feature control in structural topology optimization via level set method, Computer Methods in Applied Mechanics and Engineering, Vol.272 (2014), pp.354-378.

Langelaar, M., Topology optimization of 3D self-supporting structures for additive manufacturing, Additive Manufacturing, Vol.12 (2016), pp.60-70.

Leary, M., Merli, L., Torti, F., Mazur, M. and Brandt, M., Optimal topology for additive manufacture: a method for enabling additive manufacture of support-free optimal structures, Materials \& Design, Vol.63 (2014) pp.678-690.

Poulsen, T.A., A new scheme for imposing a minimum length scale in topology optimization, International Journal for Numerical Methods in Engineering, Vol.57, No.6 (2003), pp.741-760.

Sato, Y., Yamada, T., Izui, K. and Nishiwaki, S., Manufacturability evaluation for molded parts using fictitious physical models and its application in topology optimization, The International Journal of Advanced Manufacturing Technology, Vol.92, Issue 1-4 (2017), pp.1391-1409.

佐藤勇気, 山田崇恭, 泉井一浩, 西脇眞二, 仮想的な物理モデルに基づく幾何学的制約付きトポロジー最適化, 日本機 械学会論文集, Vol.83, No.851 (2017), DOI:10.1299/transjsme.17-00081.

Wang, M.Y., Wang, X. and Guo, D., A level set method for structural topology optimization, Computer Methods in Applied Mechanics and Engineering, Vol.192, No.1 (2003), pp.227-246.

Xia, Q., Shi, T., Wang, M.Y. and Liu, S., A level set based method for the optimization of cast part, Structural and Multidisciplinary Optimization, Vol.41, No.5 (2010), pp.735-747.

Yamada, T., Izui, K., Nishiwaki, S. and Takezawa, A., A topology optimization method based on the level set method incorporating a fictitious interface energy, Computer Methods in Applied Mechanics and Engineering, Vol.199 (2010), pp.2876-2891.

山田崇恭, 西脇眞二, 泉井一浩, 吉村允孝, 竹澤晃弘, レベルセット法による形状表現を用いたフェーズフィールド法 の考え方に基づくトポロジー最適化, 日本機械学会論文集 A 編, Vol.75, No.753 (2009), pp.550-558.

Zhou, M., Fleury, R., Shyy, Y.K. and Thomas, H.L., Progress in topology optimization with manufacturing constraints, Proc. 9th AIAA/ISSMO symposium on multidisciplinary analysis and optimization (2002), Atlanta, GA.

Zhou, M., Lazarov, B.S., Wang, F. and Sigmund, O., Minimum length scale in topology optimization by geometric constraints, Computer Methods in Applied Mechanics and Engineering, Vol.293 (2015), pp.266-282.

\section{References}

Allaire, G., Jouve, F. and Michailidis, G., Thickness control in structural optimization via a level set method, Structural and Multidisciplinary Optimization, Vol.53, No.6 (2016), pp.1349-1382. 
Allaire, G., Jouve, F. and Toader, A.M., Structural optimization using sensitivity analysis and a level-set method, Journal of Computational Physics, Vol.194, No.1 (2004), pp.363-393.

Bendsoe, M.P. and Kikuchi, N., Generating optimal topologies in structural design using a homogenization method, Computer Methods in Applied Mechanics and Engineering, Vol.71, No.2 (1988), pp.197-224.

Bendsoe, M.P. and Sigmund, O., Material interpolation schemes in topology optimization, Archive of Applied Mechanics, Vol.69 (1999), pp.635-654.

Chen, S., Wang, M.Y. and Liu, A.Q., Shape feature control in structural topology optimization, Computer-Aided Design, Vol.40, No.9 (2008), pp.951-962.

Guest, J.K., Imposing maximum length scale in topology optimization, Structural and Multidisciplinary Optimization, Vol.37, No.5 (2009), pp.463-473.

Guest, J.K., Prévost, J.H. and Belytschko, T., Achieving minimum length scale in topology optimization using nodal design variables and projection functions, International Journal for Numerical Methods in Engineering, Vol.61, No.2 (2004), pp.238-254.

Guo, X., Zhang, W. and Zhong, W., Explicit feature control in structural topology optimization via level set method, Computer Methods in Applied Mechanics and Engineering, Vol.272 (2014), pp.354-378.

Langelaar, M., Topology optimization of 3D self-supporting structures for additive manufacturing, Additive Manufacturing, Vol.12 (2016), pp.60-70.

Leary, M., Merli, L., Torti, F., Mazur, M. and Brandt, M., Optimal topology for additive manufacture: a method for enabling additive manufacture of support-free optimal structures, Materials \& Design, Vol.63 (2014) pp.678-690.

Poulsen, T.A., A new scheme for imposing a minimum length scale in topology optimization, International Journal for Numerical Methods in Engineering, Vol.57, No.6 (2003), pp.741-760.

Sato, Y., Yamada, T., Izui, K. and Nishiwaki, S., Manufacturability evaluation for molded parts using fictitious physical models and its application in topology optimization, The International Journal of Advanced Manufacturing Technology, Vol.92, Issue 1-4 (2017), pp.1391-1409.

Sato, Y., Yamada, T., Izui, K. and Nishiwaki, S., Topology optimization with geometrical constraints based on fictitious physical models, Transactions of the JSME (in Japanese), Vol.83, No.851 (2017), DOI:10.1299/transjsme.17-00081.

Wang, M.Y., Wang, X. and Guo, D., A level set method for structural topology optimization, Computer Methods in Applied Mechanics and Engineering, Vol.192, No.1 (2003), pp.227-246.

Xia, Q., Shi, T., Wang, M.Y. and Liu, S., A level set based method for the optimization of cast part, Structural and Multidisciplinary Optimization, Vol.41, No.5 (2010), pp.735-747.

Yamada, T., Izui, K., Nishiwaki, S. and Takezawa, A., A topology optimization method based on the level set method incorporating a fictitious interface energy, Computer Methods in Applied Mechanics and Engineering, Vol.199 (2010), pp.2876-2891.

Yamada, T., Nishiwaki, S., Izui, K., Yoshimura, M. and Takezawa, A., A structural optimization method incorporating level set boundary expressions based on the concept of the phase field method, Transactions of the Japan Society of Mechanical Engineers, Series A, Vol.75, No.753 (2009), pp.550-558 (in Japanese).

Zhou, M., Fleury, R., Shyy, Y.K. and Thomas, H.L., Progress in topology optimization with manufacturing constraints, Proc. 9th AIAA/ISSMO Symposium on Multidisciplinary Analysis and Optimization (2002), Atlanta, GA.

Zhou, M., Lazarov, B.S., Wang, F. and Sigmund, O., Minimum length scale in topology optimization by geometric constraints, Computer Methods in Applied Mechanics and Engineering, Vol.293 (2015), pp.266-282. 